Acta Crystallographica Section C

Crystal Structure

Communications

ISSN 0108-2701

Editor: George Ferguson

\title{
catena-Diaquatris( $\alpha$-furancarboxylato)lanthanum(III)
}

\author{
X. Li, X.-A. Chen, L. Zhao and B.-M. Chen
}

This electronic document was scanned from an archival copy of material deposited to accompany a paper published in an IUCr journal. In many cases the only accessible copy was a microfilm of a poor-quality original. 



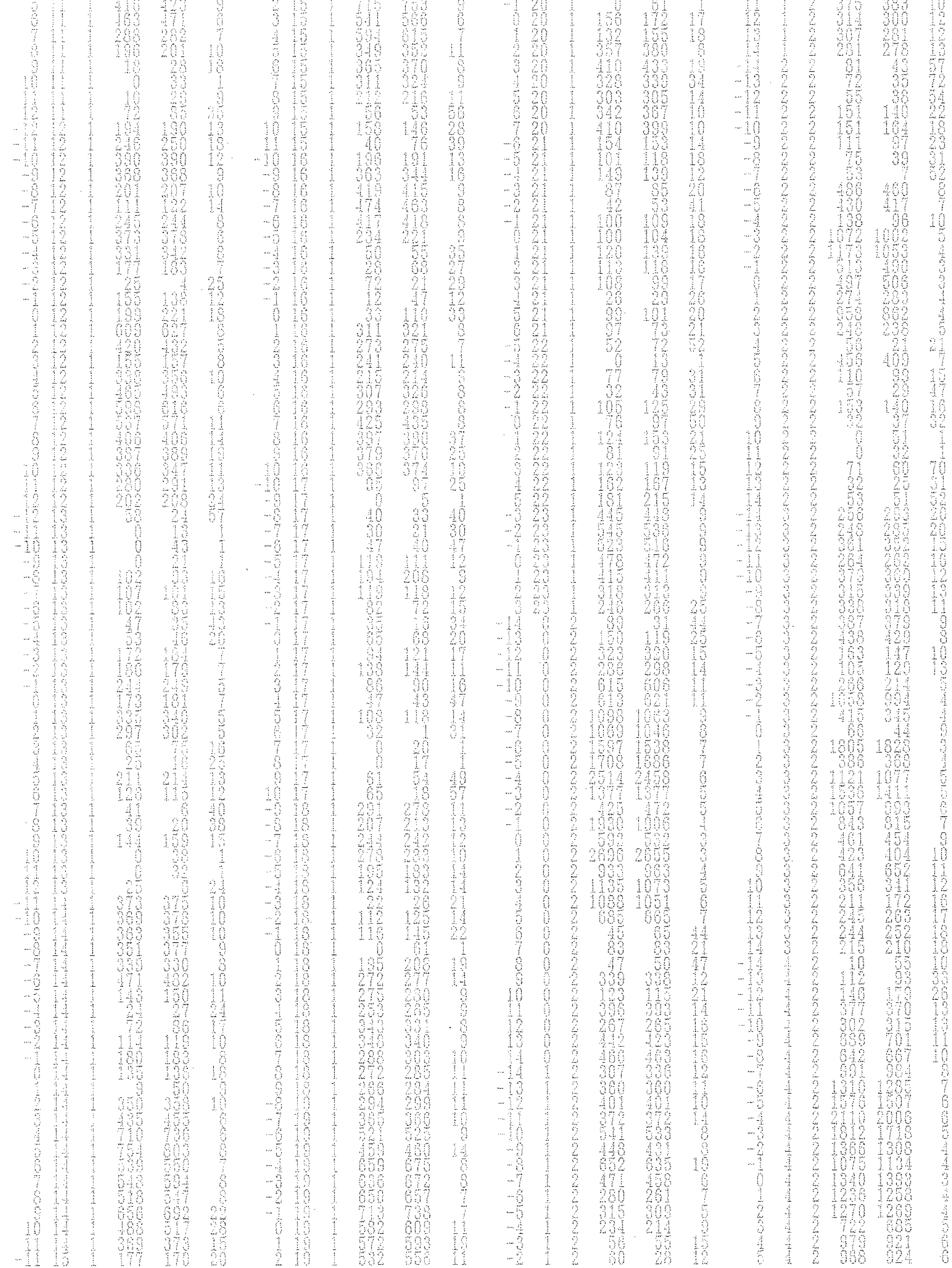




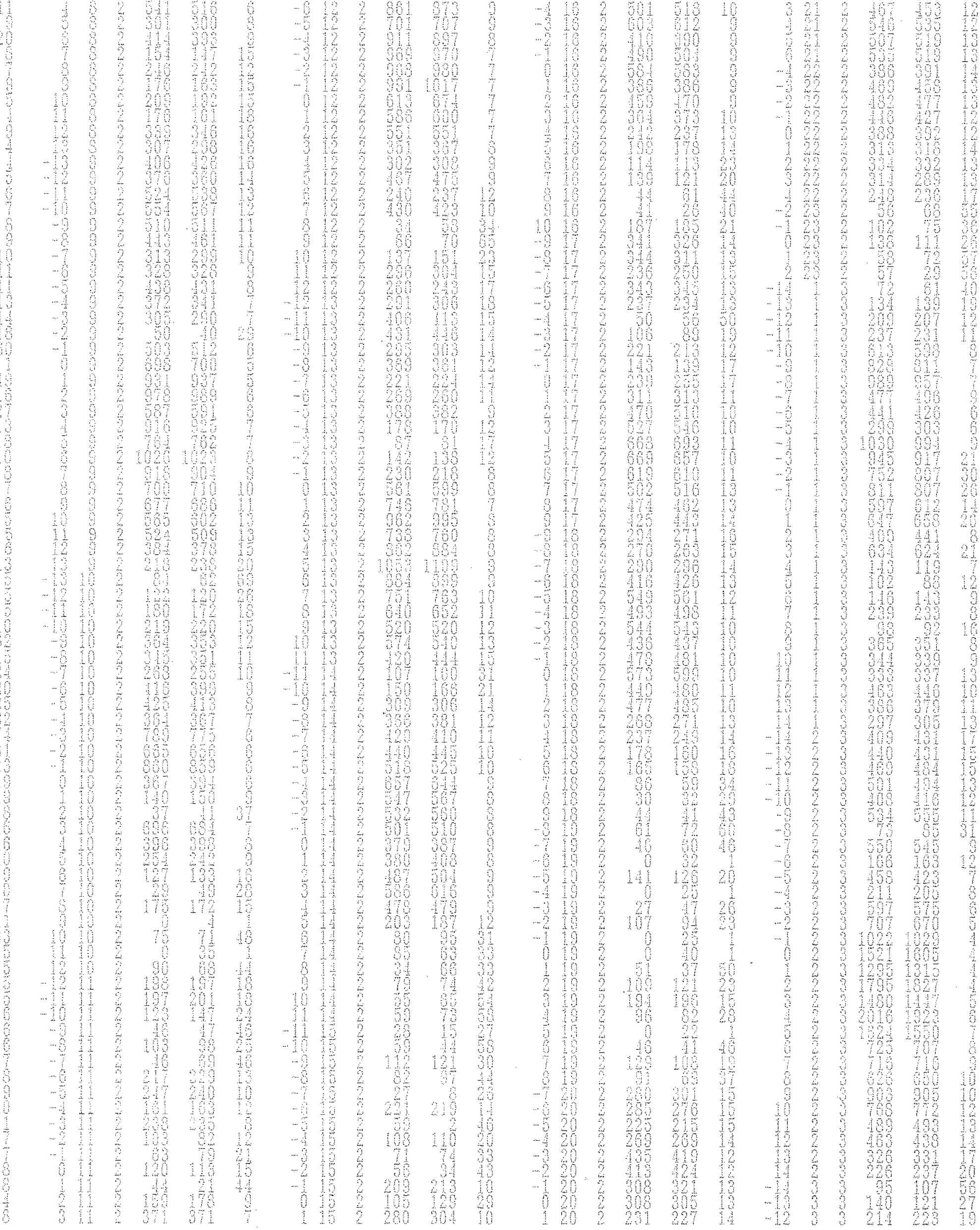




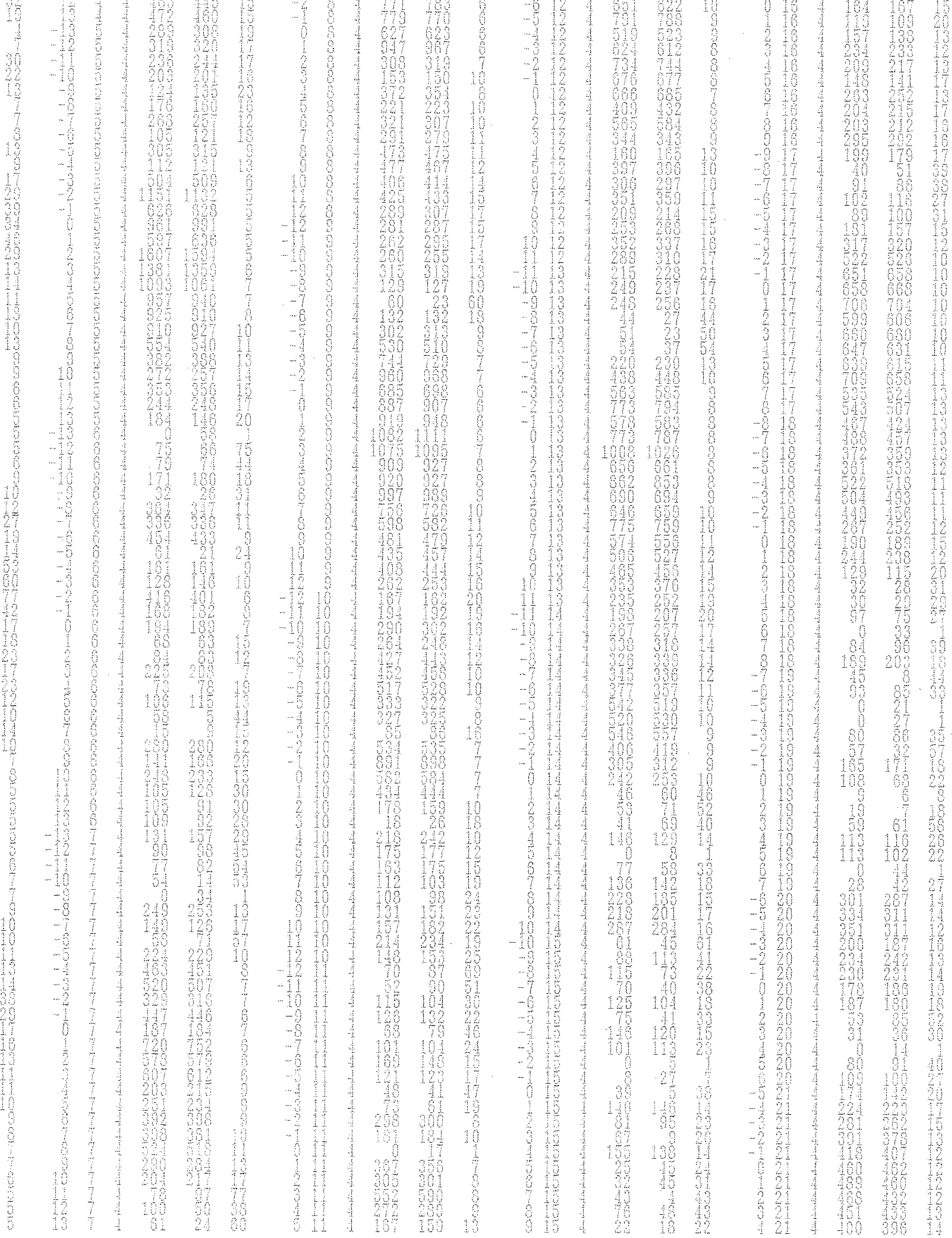




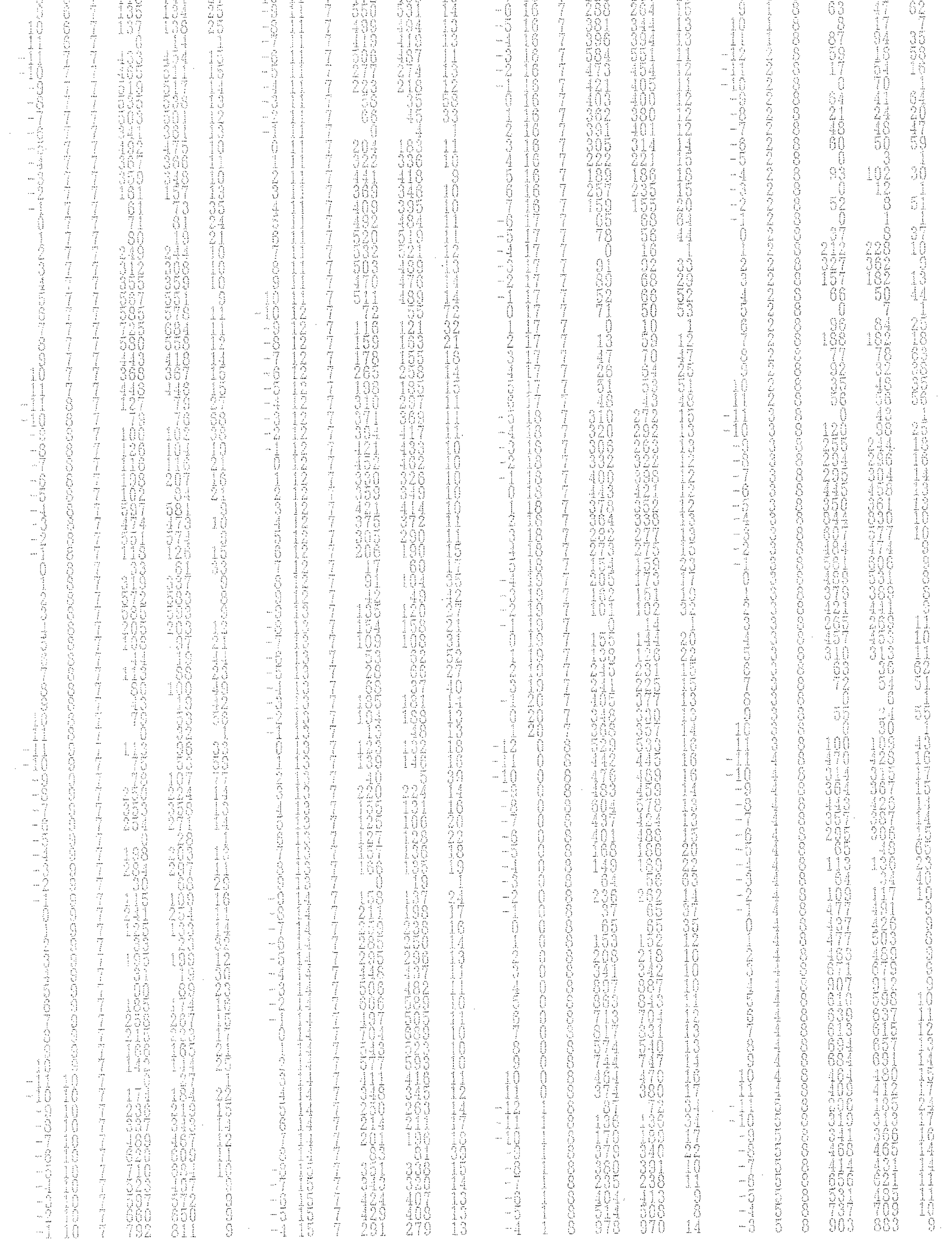




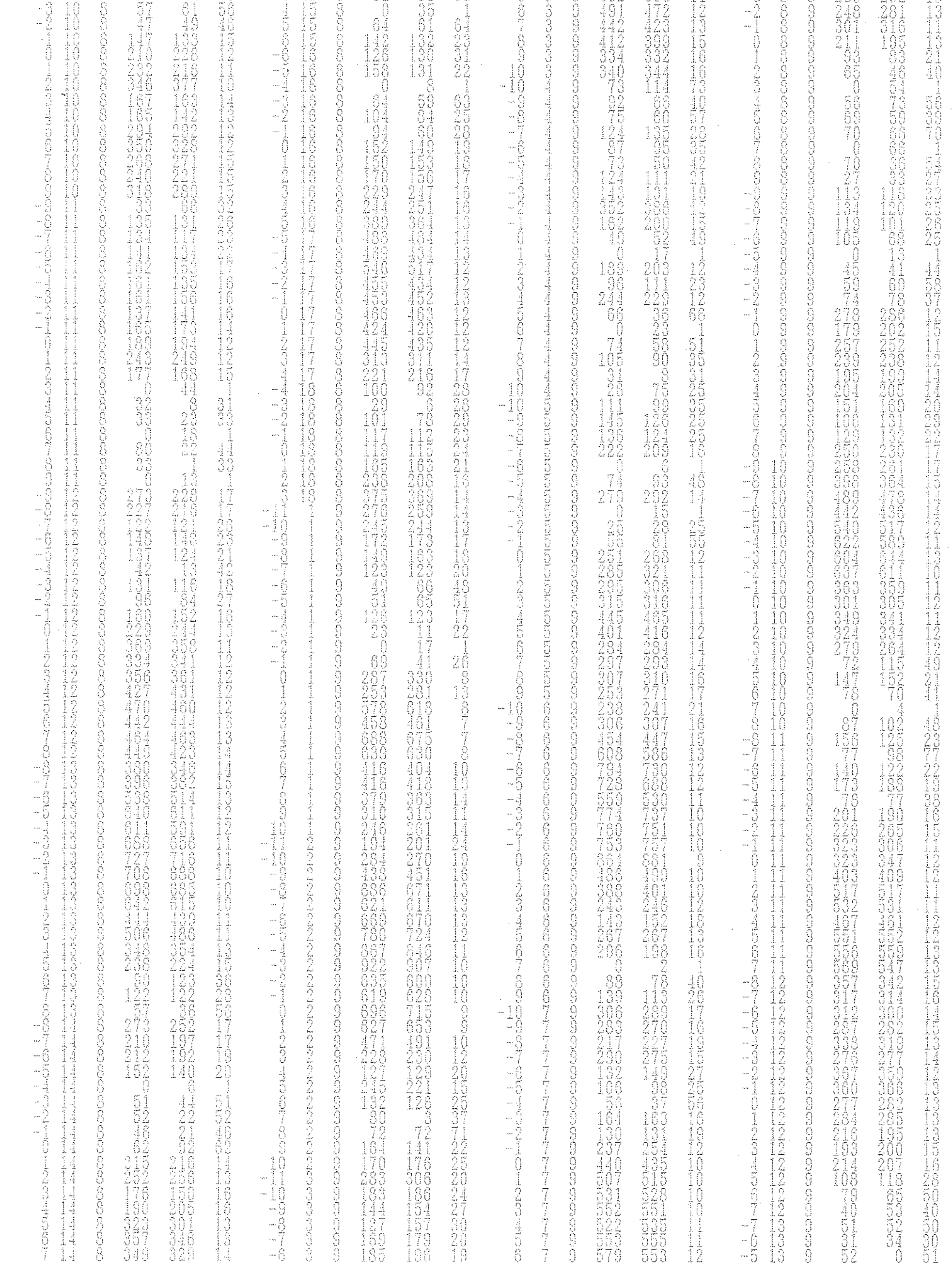




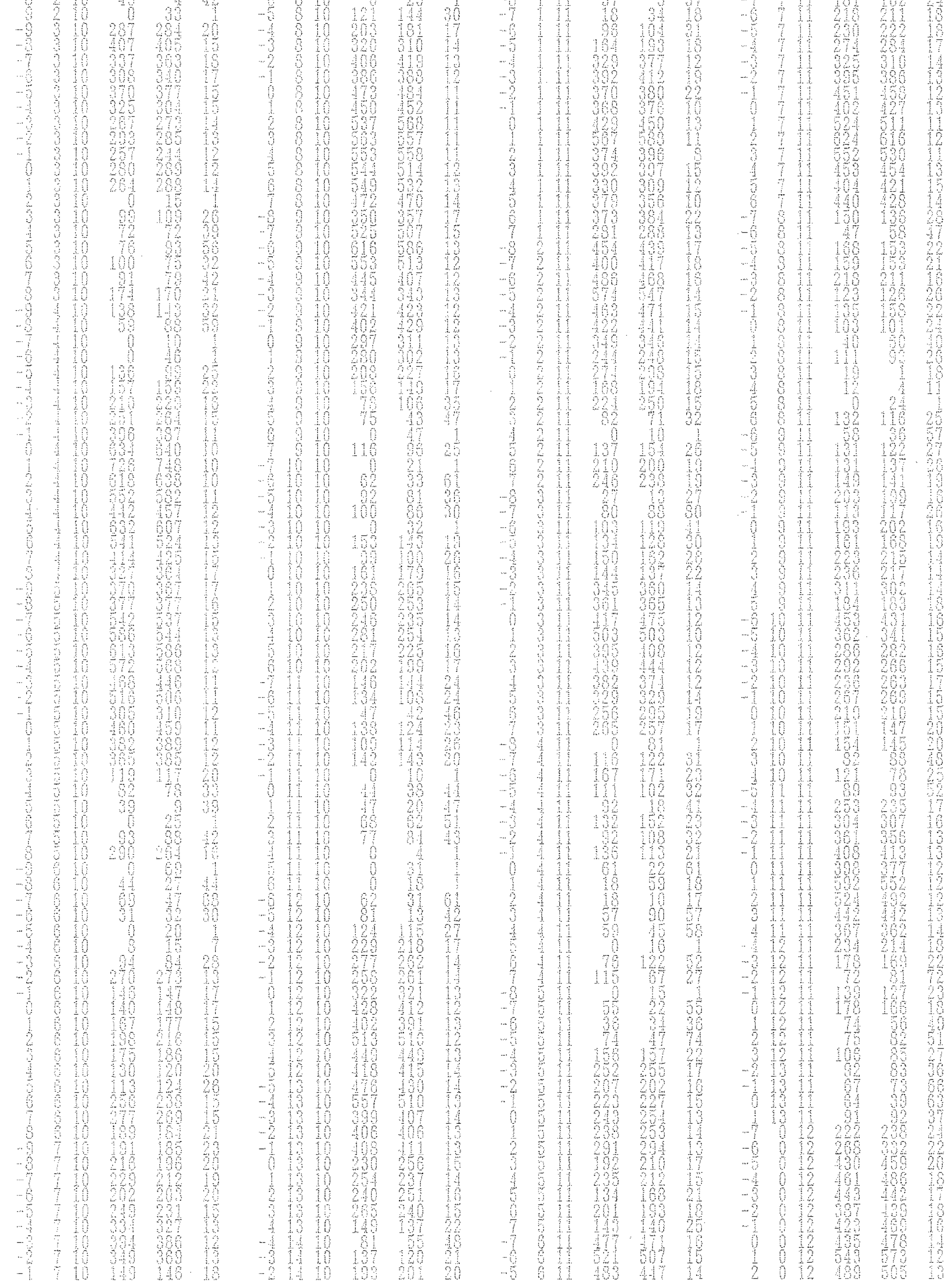




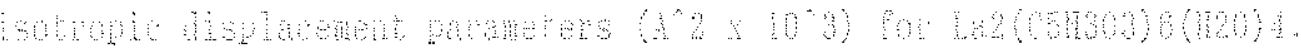





2

(1)

$29(1)$

$28(1)$

$20(1)$

810

3)(1)

$8+2$

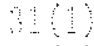

$13(2)$

$18(2)$

$8(1)$

98

2) (2)

20

$28(2)$

$88(2)$

$28(2)$

212

$40(2)$

319

$70(1)$

$7(4)$

$28(2)$

2)

1)

88

$80(8)$
अ.

(1)

211

$-2(1)$

$-1(1)$

(1)

$8(1)$

$-13)$

$+1$

$9(1)$

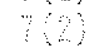

$(1)$

$-2(1)$

$-19$

$-1(1)$

$-4$

$42)$

$7(2)$

$-4(1)$

$-8(2)$

$4(2)$

$-8(8)$

$-8(0)$

$-8(1)$

$0(2)$

$8(2)$

$-18(9)$

$-12(9)$
13

62

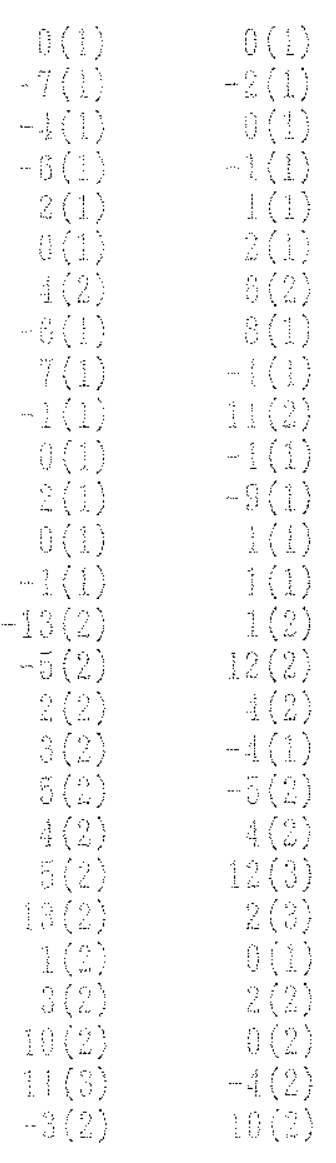

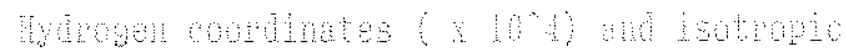

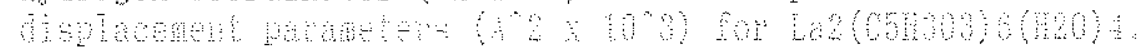

898

$78+3$

बना ()

9.

014

3 b.

\begin{tabular}{|c|c|}
\hline 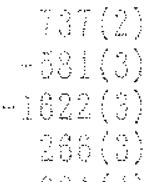 & 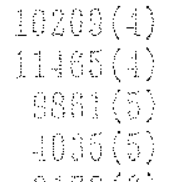 \\
\hline
\end{tabular}

